\title{
Proteomic identification of angiomotin by ProteomeLab PF-2D and correlation with clinical outcome in human clear cell renal cell carcinoma
}

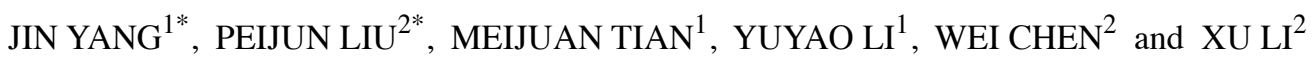 \\ ${ }^{1}$ Medical Oncology Department, ${ }^{2}$ Center for Translational Medicine, The First Affiliated Hospital, \\ College of Medicine, Xi'an Jiaotong University, Xi'an 710061, P.R. China
}

Received January 17, 2013; Accepted March 13, 2013

DOI: $10.3892 /$ ijo.2013.1889

\begin{abstract}
Identification of new therapeutic and prognostic biomarkers for clear cell renal cell carcinoma (ccRCC) is urgently required since most patients are in advanced stages of ccRCC at initial diagnosis and the recurrence rate is high. Differentially expressed proteins between the ccRCC cell line RLC-310 and the normal renal cell line HK-2 were identified by a comparative proteomic approach based on a protein fractionation two-dimensional (PF-2D) liquid-phase fractionation system and capillary liquid chromatography electrospray ionization mass spectrometry/mass spectrometry (LC-ESI-MS/ MS). Differentially expressed proteins $(n=196)$ were identified. Of the 13 differentially expressed proteins newly discovered in ccRCC, angiomotin (Amot) was the focus of this study since its role in ccRCC progression has been obscure. The overexpression of Amot in ccRCC tissues was confirmed by comparing Amot expression in 18 primary ccRCC tissues and adjacent normal renal tissues (ANRT) using western blot analysis. Quantitative RT-PCR using 127 ccRCC tissues revealed that high levels of Amot transcripts were associated with poor differentiation, venous invasion and decreased survival $(\mathrm{p}<0.0001,<0.05$ and $<0.05)$. Multivariate analysis indicated that Amot transcript was an independent prognostic factor for the survival of ccRCC patients $(\mathrm{p}<0.05)$. These data suggest that Amot may serve as a novel prognostic factor of ccRCC.
\end{abstract}

\section{Introduction}

Of all types of cancers, kidney cancer, which accounts for $>83,000$ deaths per year worldwide, ranks the sixth in the age-

Correspondence to: Professor $\mathrm{Xu} \mathrm{Li}$, Center for Translational Medicine, The First Affiliated Hospital, College of Medicine, Xi'an Jiaotong University, 277 YanTa West Road, Xi'an 710061, P.R. China E-mail:drlixu56@yahoo.com.cn

\section{${ }^{*}$ Contributed equally}

Key words: angiomotin, clear-cell renal cell carcinoma, proteomics, PF-2D, RLC-310, HK-2 standardized incidence rate (per 100,000), with 5.8 in females and 11.8 in males in developed countries and 2.5 in males and 1.4 in females in developing countries (1). Renal cell carcinoma (RCC) constitutes the most prevalent form of kidney neoplasm in the adult population. Most RCC patients are found to have metastatic disease at initial diagnosis and are, therefore, defined as patients with advanced RCC. Immunotherapy with cytokines is the standard systemic treatment for advanced RCC. However, advanced RCC is inherently resistant to standard systemic treatment regimens (2). It has been reported that high-dose interleukin-2 (IL-2) or interferon (IFN)- $\alpha$ shows only $10-15 \%$ response rates in selected patients $(3,4)$.

The increased knowledge of the molecular pathways involved in the proliferation and angiogenesis of RCC has led to the development of targeted therapy. Since 2005, six new targeted therapy drugs (Sunitinib, Sorafenib, Pazopanib, Bevacizumab, Temsirolimus and Everolimus) with proven efficacy have been approved for treatment of metastatic RCC (5). However, the downside is that our knowledge of the mechanisms of action of these drugs and the intrinsic and extrinsic mechanisms of drug resistance do not evolve equally fast and many questions remain unanswered.

Currently, targeted RCC therapy drugs suppress tumor angiogenesis and abnormal proliferation of tumor cells mostly by targeting to VHL/HIF signaling pathway and related growth factors $(6,7)$. As we know, kidney cancer cell proliferation and angiogenesis are the results of the joint action of multiple molecular pathways and there exists a compensatory relationship among these pathways. When the VEGF/RTK signaling pathway is suppressed, other compensation pathways may be activated. Therefore, a single targeted drug often has limited therapeutic effect. It is generally believed that better treatment effect can be achieved only by the combined application of drugs targeting to different angiogenesis and cell proliferation signal pathways $(8,9)$. In recent years, it has become a hot spot to research on drugs targeting to the VEGF/RTKindependent angiogenesis/cell proliferation pathways.

Comparative proteomic strategies have been introduced to identification of targeted proteins in cancer research (10-12). The two-dimensional polyacrylamide gel electrophoresis (2-DE)/mass spectrometry (MS) approach is one of the most popular tools for profiling the proteome in human diseases. 
To date, numerous proteomics studies on RCC base on 2-DE/ MS have been reported (11,13-15). In our previous research, 31 proteins differentially expressed between clear-cell RCC (ccRCC) cell line RLC-310 and renal normal cell line HK-2 were identified by the 2-DE/MS method (16). RCCs comprise a heterogeneous group of tumors with distinct genetic backgrounds and different biological characteristics. The most common subtype of RCCs is clear-cell RCC, which accounts for $>80 \%$ of RCCs.

However, the intrinsic property of 2-DE leads to an underrepresentation of the proteins that are highly hydrophobic or highly basic or lowly abundant, or the proteins with high molecular weight or extremely isoelectric points. Recently, several new technologies have been developed to avoid 2-DE weakness. The PF-2D separation technology employs isoelectric focusing chromatography for the first dimension and reverse-phase chromatography for the second dimension. The PF-2D combined with capillary LC-ESI-MS/MS has been used to improve protease detection of the more acidic, basic and hydrophobic proteins and to increase reproducibility and throughput of the extremely isoelectric points typically observed with 2-DE analysis.

In this study, we compared the global protein profiles of ccRCC RLC-310 and normal renal cell line HK-2 using a PF-2D/capillary LC-ESI-MS/MS based approach. Thirteen differentially expressed proteins were newly discovered in RCC and angiomotin (Amot) was a newly identified differentially expressed protein in ccRCC cell line. We found that high levels of Amot transcript were associated with poor differentiation, venous invasion and decreased survival. Amot transcript was an independent prognostic factor for ccRCC. These data suggest that Amot may serve as a novel prognostic factor for ccRCC.

\section{Materials and methods}

Materials. The reagents used in the study are as follows: RPMI-1640 and fetal bovine serum (FBS) (Gibco/Invitrogen, Carlsbad,CA,USA); Transwell inserts (Costar,Cambridge,MA, USA); ProteomeLab ${ }^{\mathrm{TM}}$ PF-2D system and its matched separation kit (Beckman Coulter, Fullerton, CA, USA); LC-ESI-MS/ MS instrument (Thermo Finnigan US Companies, San Jose, CA, USA); rabbit anti-human Amot polyclonal antibody (Abcam, Cambridge, MA, USA); goat anti-rabbit secondary antibody and rabbit anti-human $\beta$-actin polyclonal antibody (Jackson Co., Lansing, MI, USA); TRIzol reagent (Invitrogen, Carlsbad, CA, USA); RNAfast200 (Flytech Biotechnology, Shanghai, China); one-step SYBR RNA PCR kit II (Takara Biomedical, Dalian, China); TPCK-trypsin, trifluoroacetic acid (TFA), n-octyl glucoside and protease inhibitors (Sigma Co., St. Louis, MO, USA).

Clinical samples. Fresh frozen surgical specimens of primary ccRCC tissues paired with ANRT were obtained from 127 patients, who were treated with nephrectomy at The First Affiliated Hospital of Xi'an Jiaotong University between January 2005 and October 2007 and stored at $-80^{\circ} \mathrm{C}$ until use. The presence of tumor cells in the collected tissues was verified by a consultant pathologist, who examined H\&E stained frozen sections. The histological types were determined according to the World Health Organization classification. The tumors were staged according to Robson staging criteria and the histodifferentiation grading of the tumors was assigned according to the criteria established by the World Health Organization in 1997. This study was approved by the Institutional Ethics Committee of Xi'an Jiaotong University. The informed consent for the use of the samples was obtained from each patient. Patients were routinely followed up on a regular basis and details were stored in a database.

\section{Methods}

Cell line culture and sample preparation. RLC-310 and HK-2 cell lines were cultured in RPMI-1640 supplemented with $10 \% \mathrm{FBS}$ at $37^{\circ} \mathrm{C}$ in $5 \% \mathrm{CO}_{2}$. The cells were harvested at the exponential growth phase by trypsinization, washed with ice-cold PBS, counted and homogenized in lysis buffer (6 M urea, $2 \mathrm{M}$ thiourea, $10 \%$ glycerol, $50 \mathrm{mM}$ Tris, $2 \%$ n-octyl glucoside, $5 \mathrm{mM}$ TCEP and $1 \mathrm{mM}$ protease inhibitors) on ice. Suspensions were incubated for $1 \mathrm{~h}$ at $4^{\circ} \mathrm{C}$ and centrifuged at $20000 \mathrm{x} \mathrm{g}$ for $60 \mathrm{~min}$. The supernatants were stored at $-80^{\circ} \mathrm{C}$ until use. The total protein concentration was determined by the Bradford method using bovine serum albumin as the standard.

Two-dimensional liquid phase fractionation $(P F-2 D)$ separation and analysis. The ProteomeLab PF 2D Chemistry kit includes a chromatofocusing high performance computing facility (HPCF) column (first dimension), a nonporous high performance reversed-phase (HPRP) column (second dimension), a start buffer ( $\mathrm{pH}$ 8.5) and an elution buffer ( $\mathrm{pH} 4.0)$. The first dimension separation consists of chromatofocusing, based on charge. Chromatofocusing was carried out on the $\mathrm{CF}$ column by mixing two buffers with different $\mathrm{pH}$ values, Start buffer ( $\mathrm{pH} 8.5)$ and Eluent buffer $(\mathrm{pH} 4.0)$, to create a linear $\mathrm{pH}$ gradient from 8.5 to 4.0 , which was followed by a wash buffer comprising $1 \mathrm{M} \mathrm{NaCl}$. The $\mathrm{pH}$ gradient was achieved by introducing increasing amounts of the eluent buffer ( $\mathrm{pH} \mathrm{4.0)}$ at a flow rate of $0.2 \mathrm{ml} / \mathrm{min}$ over $90 \mathrm{~min}$. Protein samples $(\leq 5.0 \mathrm{mg})$, prepared in Start buffer, were loaded. Protein peaks in Eluent buffer were monitored by absorbance at $280 \mathrm{~nm}$. The first dimension fractions were collected in 96-well plates (every $0.3 \mathrm{pH}$ units during the $\mathrm{pH}$ gradient portion of the run or every 5 min during the other stages of the run, before the $\mathrm{pH}$ gradient and during salt washing) and introduced into the second dimensional reversed phase chromatography, which separated proteins based on hydrophobicity.

In the second dimension, each fraction $(500 \mu \mathrm{l})$ was sequentially analyzed by reversed phase HPLC at a constant temperature of $50^{\circ} \mathrm{C}$. Proteins were separated at a flow rate of $0.75 \mathrm{ml} / \mathrm{min}$ on a non-porous $\mathrm{C} 18$ reversed phase column using $3.33 \% \mathrm{~B} / \mathrm{min}$ linear gradient in which solvent $\mathrm{A}$ was $0.1 \%$ aqueous TFA and solvent $\mathrm{B}$ was $0.08 \%$ TFA in acetonitrile. Proteins were monitored at $214 \mathrm{~nm}$. The reversed phase fractions were collected by $0.25 \mathrm{~min} /$ tube and stored at $-80^{\circ} \mathrm{C}$ for further analysis. The fractions were also collected into 96-deepwell plates for mass spectrometry analysis.

The hardware was controlled by 32 Karat software. With this system, the first and second dimensions occurred sequentially in an automatic manner. For one-dimensional LC, the 
percentages of the protein eluted on different columns and at different $\mathrm{pH}$ conditions were determined by calculating the peak area of the protein monitored at $214 \mathrm{~nm}$, a wavelength at which the peak area was directly proportional to the quantity of the protein(s). Mass spectrometry was carried out to confirm the composition of the protein peaks. Comparison of two separate UV/pI maps consisting of the entire $\mathrm{pH}$ gradient was performed by a module (DeltaVue) of the Mapping Tools data processing software. A second module (MultiVue) enabled the analysis of a $\mathrm{pH}$ lane selected from multiple sample runs.

Capillary LC-ESI-MS/MS analysis and database searches. The reversed phase fractions $(200 \mu \mathrm{l})$ obtained from the two-dimensional LC were concentrated to 5-10 $\mu \mathrm{l}$ using a SpeedVac concentrator, and $1 \mathrm{M} \mathrm{NH}_{4} \mathrm{HCO}_{3}$ was added to the residues to neutralize the samples to $\mathrm{pH}$ 8.0. The samples were then digested at $37^{\circ} \mathrm{C}$ for $20 \mathrm{~h}$ with sequencing grade modified trypsin at an enzyme-to-substrate ratio of 1:50. The digestion was stopped by adding 10\% TFA and the digestion product was freeze-dried; then 1D-LC ESI-MS/MS was performed using an LTQ linear IT mass spectrometer with the CF column equilibrated with $0.1 \%$ formic acid in $95 \%$ water and 5\% acetonitrile. The system was fitted with a C18 RP column. The mobile phase A was $0.1 \%$ formic acid in water and the mobile phase B was $0.1 \%$ formic acid in acetonitrile. Each sample was dissolved to $5 \mu \mathrm{l}$ in $0.1 \%$ formic acid in water and auto-injected to the C18 Trap desalination column and then separated on the $\mathrm{C} 18$ reversed-phase column. The system was set as follows: injection mode, microspray; detection method, positive ions; capillary temperature, $170^{\circ} \mathrm{C}$. The gradients were set as follows: 0-20 min, B fluid linear gradient from 4 to $50 \% ; 20-24 \mathrm{~min}$, B linear gradient of liquid from 50 to $100 \%$; $24-30 \mathrm{~min}$, B solution maintained at $100 \%$. The LTQ linear IT mass spectrometer was set so that one full MS scan was followed by $20 \mathrm{MS} / \mathrm{MS}$ scans on the 10 most intense ions from the MS spectrum.

MS/MS spectra were automatically searched against the non-redundant International Protein Index (IPI) human protein database (version 3.53) using the TurboSEQUEST program in the Bioworks Browser software suite. The peptides were constrained to be tryptic and up to two missed cleavages were allowed. The allowed mass tolerance was $3.0 \mathrm{Da}$ for the precursor ions and 1.0 Da for the fragment ions. The stringent protein identification criteria were based on $\Delta \mathrm{Cn}$ $\geq 0.1$ and cross-correlation scores (Xcorr, one charge $\geq 1.9$, two charges $\geq 2.2$, three charges $\geq 3.75$ ). Only proteins identified by at least two peptide matches were reported as differentially expressed proteins.

Tissue processing and RNA and protein extraction. Frozen sections of tissues were cut at a thickness of 5-10 $\mu \mathrm{m}$ and kept for routine histology. Another 15-20 sections were mixed and homogenised in ice-cold RNA extraction solution using a hand-held homogeniser. The concentration of RNA was determined using a UV spectrophotometer. The rest of the tissues were used for protein extraction.

$R T-P C R$ and quantitative RT-PCR. The total RNA from cells and tissues was extracted using the TRIzol Reagent according to the manufacturer's instructions. cDNA was prepared by reverse transcription of $1 \mathrm{mg}$ total RNA using oligo(dT) 15 primer and reverse transcriptase. The primer sequences and the expected sizes of PCR products were as follows: Amot, sense 5'-CAG CAG CAG CAG CCA CAG-3' and antisense 5'-CCA CCT TCT CAT AGC ATC CTT CC-3' (196 bp); $\beta$-actin, sense 5'-ATC GTG CGT GAC ATT AAG GAG AAG-3' and antisense 5'-AGG AAG GAA GGC TGG AAG AGT G-3' (179 bp). RT-PCR was performed using a one-step SYBR RNA PCR kit II according to the manufacturer's instructions in the following procedure: reverse transcription at $48^{\circ} \mathrm{C}$ for $30 \mathrm{~min}$ and denaturation at $95^{\circ} \mathrm{C}$ for $1 \mathrm{~min}$; amplification for 35 cycles at $94^{\circ} \mathrm{C}$ for $0.5 \mathrm{~min}$, annealation at $60^{\circ} \mathrm{C}$ for $0.5 \mathrm{~min}$ and extension at $70^{\circ} \mathrm{C}$ for $0.5 \mathrm{~min}$; then a terminal elongation step at $72^{\circ} \mathrm{C}$ for 5 min and a final holding stage at $4^{\circ} \mathrm{C}$. Reactions were run on an ABI 9700 Thermocycler (Applied Biosystems Inc., Foster City, CA, USA). PCR products were separated by electrophoresis on $1.2 \%$ agarose gels. Ethidium bromide-stained bands were visualized by UV illumination and quantified using the Dolphin-DOC Gel imaging system (Molecular Dynamics, Sunnyvale, CA, USA).

The miRNA quantification was done using a previously described method (17). RNA samples used in qPCR validation experiments were isolated from 127 primary ccRCC tissues paired with ANRT. Primer 5 software was used to design the primer sequences. The sequences of the respective primers were: angiomotin (5'-AAG CGT TGC CTT GAC ATG GAG-3' and 5'-GGA ACG CTG CTG GAG TAC TTT GA-3'), $\beta$-actin (5'-TGG CAC CCA GCA CAA TGA A-3' and 5'-CTA AGT CAT AGT CCG CCT AGA AGC A-3'). First, $100 \mathrm{ng}$ of total RNA was reverse transcribed by incubation at $42^{\circ} \mathrm{C}$ for $60 \mathrm{~min}$ and $70^{\circ} \mathrm{C}$ for $15 \mathrm{~min}$ in a 7900 Thermocycler (Applied Biosystems, Carlsbad, CA, USA) using $100 \mathrm{U}$ of M-MLV reverse transcriptase (Takara: D2639A) and $1 \mu \mathrm{M}$ stem-loop RT primer. The samples were then held at $4^{\circ} \mathrm{C}$. Real-time PCR was performed using Platinum SYBR Green qPCR SuperMix-UDG (Invitrogen: 11733-038). All reactions were run in triplicate. The $\Delta \Delta C \mathrm{C}$ method was used to determine the expression differences between clinical outcomes (18).

Western blot analysis. Tissue and cell protein extracts were collected after sonication with $2 \mathrm{X}$ sample buffer $(0.25 \mathrm{M}$ Tris- $\mathrm{HCl}, 10 \%$ 2-mercaptoethanol, 4\% sodium dodecyl sulphate and $10 \%$ sucrose). The protein concentration was determined by Bradford method using bovine serum albumin as the standard. A total of $20 \mu \mathrm{g}$ of each protein sample was run on a $12 \%$ SDS-PAGE gel and transferred onto nitrocellulose membranes using a hygro-blotter. Non-specific binding was blocked with a buffer containing $0.1 \%$ Tween-20 and $5 \%$ non-fat dried milk for $1 \mathrm{~h}$ at room temperature and subsequently incubated overnight at $4{ }^{\circ} \mathrm{C}$ with anti-Amot antibody $(1 \mu \mathrm{g} / \mathrm{ml}) . \beta$-actin (dilution at $1: 1,000)$ was used as an internal positive control. The antibody-bound membranes were then incubated for $1 \mathrm{~h}$ at $37^{\circ} \mathrm{C}$ with anti-rabbit horseradish peroxidase-conjugated IgG secondary antibody. Protein bands for immunoblot analysis were detected on X-ray film using enhanced chemiluminescence (ECL) chemiluminescence reagent. Gels and the film were scanned using a Personal Densitometer SI (Leica, Germany) and analysed using Gel-Pro Analyzer 4 Image software. 
A

First dimension

(high performance computing facility (HPCF))
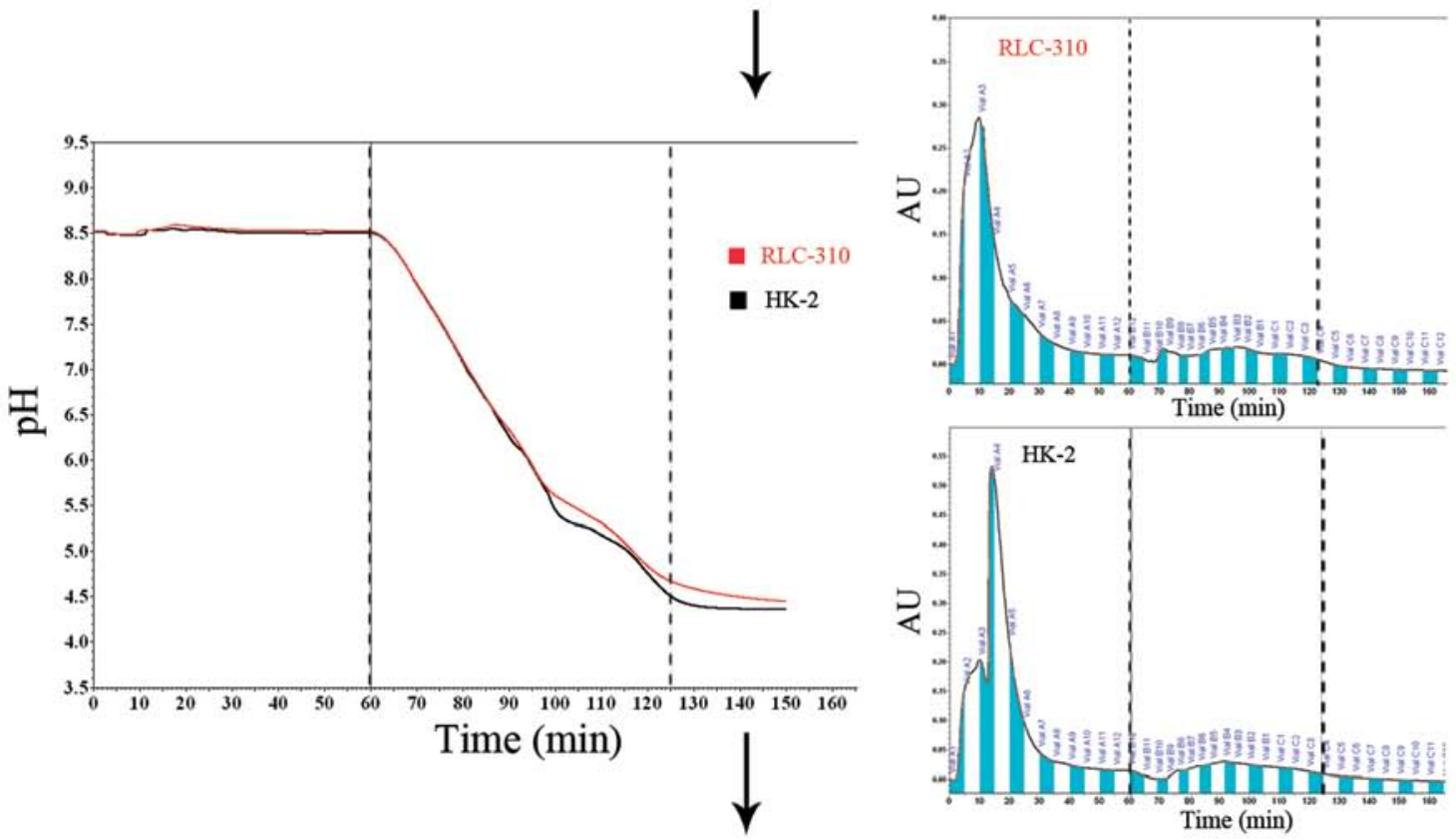

B (high performance reversed-phase (HPRP))
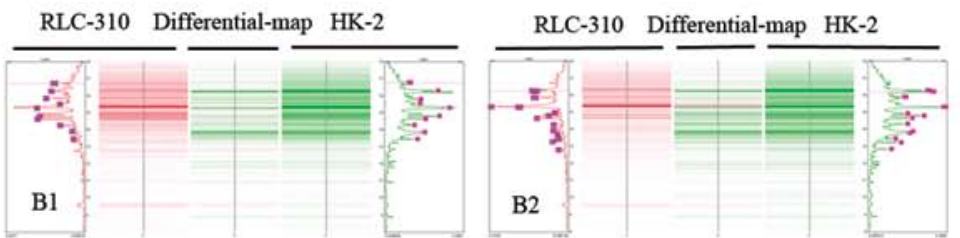

RLC-310 Differential-map HK-2
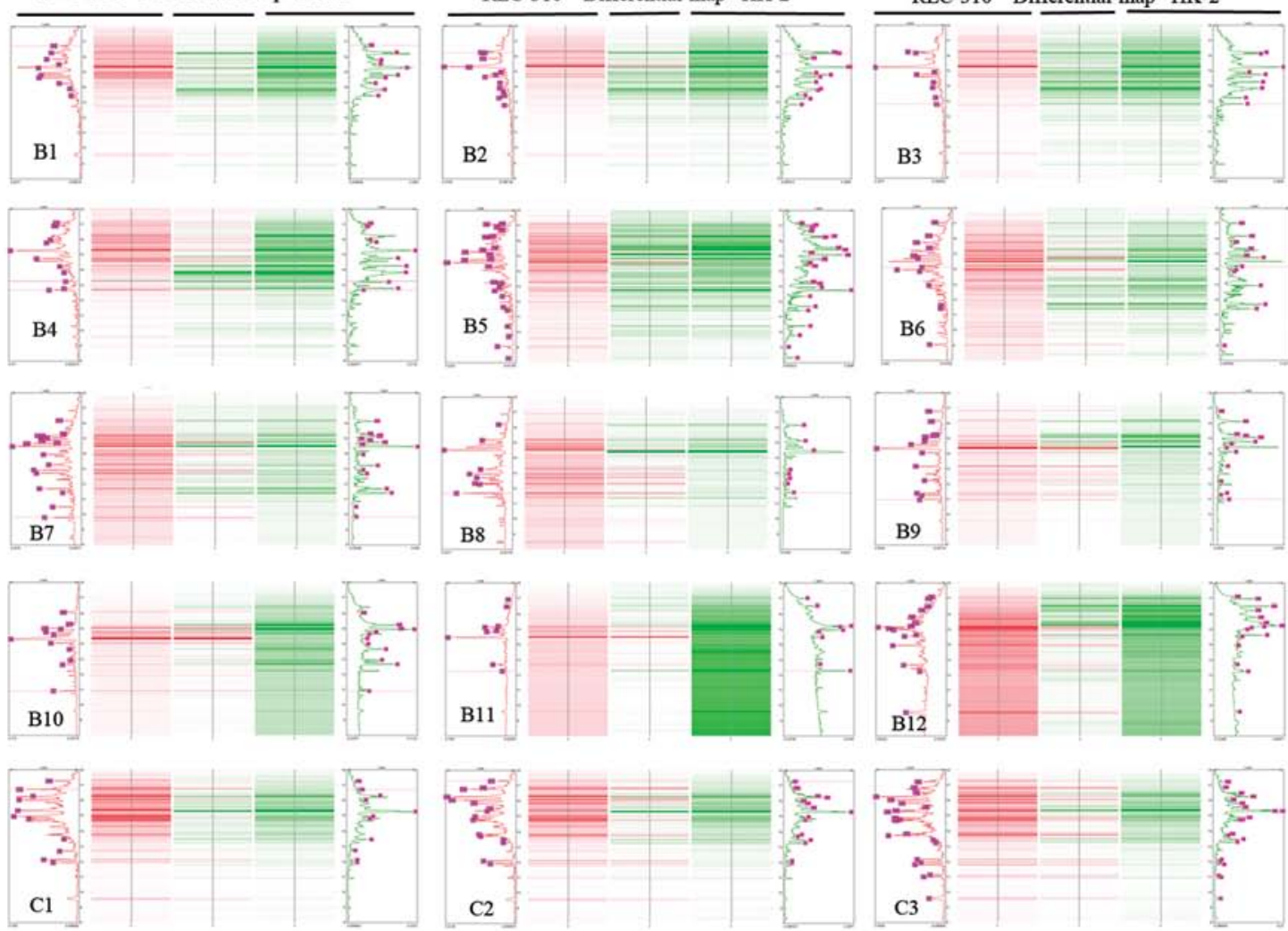

Figure 1. Chromatographic analysis of proteins of RLC-310 and HK-2 cell lines using ProteomeLab PF 2D. (A) Chromatofocusing of total proteins in a $\mathrm{pH}$ gradient. In the chromatogram, the $\mathrm{X}$-axis corresponds to the retention time in the column, the $\mathrm{Y}$-axis (left) to the $\mathrm{pH}$ and the $\mathrm{Y}$-axis (right) to the $\mathrm{AU}$ (UV absorbance). (B) Resolution of ProteomeLab PF-2D in a virtual gel given by ProteoVue software. Fifteen fractions were separated in pH gradient 8.5-4.5 and by hydrophobicity. Comparison of two aligned peaks in (A) displayed a quantitative difference in protein content measured by peak area (volume). Color scheme ranged from purple (low absorbance) to red (high absorbance). The difference between absorbencies was shown in the middle as either a red or green band, representing the sample with greater absorbance at a specific peak. 
Table I. Summary of fractions selected for mass spectrometry analyses.

\begin{tabular}{lccc}
\hline & \multicolumn{2}{c}{ Fraction coordinates } & \\
\cline { 2 - 3 } Fraction ID & $\mathrm{pH}$ & Retention times (RT) & Peak area ratio (R/H) \\
\hline RLC-310 $\left(\mathrm{B5}^{\mathrm{a}}-38^{\mathrm{b}}\right)$ & $6.53-6.23$ & $12.64-12.91$ & 2.378 \\
RLC-310 $\left(\mathrm{B}^{\mathrm{a}}-44^{\mathrm{b}}\right)$ & $6.83-8.03$ & $13.89-14.09$ & 302.018 \\
RLC-310 $\left(\mathrm{B}^{\mathrm{a}}-31^{\mathrm{b}}\right)$ & $7.73-7.43$ & $11.21-11.33$ & 302.018 \\
RLC-310 $\left(\mathrm{B}^{\mathrm{a}}-32^{\mathrm{b}}\right)$ & $7.73-7.43$ & $11.33-11.47$ & 19.108 \\
RLC-310 $\left(\mathrm{B} 10^{\mathrm{a}}-34^{\mathrm{b}}\right)$ & $8.03-7.73$ & $10.86-11.03$ & 19.108 \\
RLC-310 $\left(\mathrm{B} 10^{\mathrm{a}}-47^{\mathrm{b}}\right)$ & $8.03-7.73$ & $14.24-14.54$ & 11.298 \\
RLC-310 $\left(\mathrm{B} 10^{\mathrm{a}}-48^{\mathrm{b}}\right)$ & $8.03-7.73$ & $14.69-14.92$ & 3.828 \\
RLC-310 $\left(\mathrm{C} 1^{\mathrm{a}}-63^{\mathrm{b}}\right)$ & $5.25-5.10$ & $18.48-18.67$ & 21.031 \\
HK-2 $\left(\mathrm{B} 1^{\mathrm{a}}-42^{\mathrm{b}}\right)$ & $5.47-5.32$ & $13.54-14.16$ & 0.178 \\
HK-2 $\left(\mathrm{B} 2^{\mathrm{a}}-41^{\mathrm{b}}\right)$ & $5.63-5.47$ & $13.29-14.09$ & 0.171 \\
HK-2 $\left(B 2^{\mathrm{a}}-65^{\mathrm{b}}\right)$ & $5.63-5.47$ & $18.80-19.25$ & 0.154 \\
HK-2 $\left(B 3^{\mathrm{a}}-45^{\mathrm{b}}\right)$ & $5.92-5.63$ & $14.21-14.43$ & 0.149 \\
\hline
\end{tabular}

Corresponding peak heights are listed as absorbance units at $214 \mathrm{~nm}$. ${ }^{\mathrm{a}}$ Fractions collected in the first dimension chromatofocusing chromatography. ${ }^{b}$ Fractions collected in the second dimension reverse-phase chromatography; R/H, protein peak area of RLC-310/protein peak area of HK-2 in the second dimension reverse-phase chromatography.

Statistical analysis. Statistical analyses were conducted with SPSS 13.0 software. The differences between the cancer tissue and the adjacent tissues in the western blotting of Amot were assessed using the paired t-test. The relevance analysis of the Amot transcript expression and clinicopathological parameters was performed by the Kruskal-Wallis test and the cross-tabs $\chi^{2}$ test. Survival curves were generated by using the KaplanMeier method. The statistical analyses were performed by using the log-rank test. Multivariate analyses were performed using the Cox proportional hazard model. Statistical significance was defined as $\mathrm{p}<0.05$.

\section{Results}

Comparative proteomic analysis of $R L C-310$ and $H K$-2. In the ProteomeLab PF-2D system, $2.5 \mathrm{mg}$ of protein extract from ccRCC cell line RLC-310 or normal renal cell line HK-2 was injected into the column. The virtual 2-D gel given by the software ProteoVue showed the first- and second-dimension separation of proteins by their isoelectric points (pI) (Fig. 1A) and hydrophobicity (Fig. 1B). For each cell line, 15 protein fractions were collected in the $8.5-4.5-\mathrm{pH}$ gradient in the second dimension using the high performance reverse-phase chromatography (buffer run: 60-125 min). Each obtained fraction showed $\leq 13$ peaks or bands on average and the protein fractions from the two cell lines showed a total of $\sim 400$ bands (Fig. 1). We only considered peaks or bands that had a minimal absorbance $(0.04 \mu \mathrm{A})$ and a protein peak area ratio $>2$. Ultimately, 12 bands were excised for identification using capillary liquid chromatography electrospray ionization mass spectrometry/mass spectrometry (LC-ESI-MS/MS) (Table I).

In the tandem mass spectrometry, eight mother-ions were chosen from each protein sample for secondary mass spectrometry according to the level of the mass spectrogram and ultimately, the peptide mass of each protein sample was calculated and the MS/MS map (fragment ion mass) was obtained. The amino acid sequence of each peptide fragment was obtained by analyzing the secondary mass spectrometry results of bn and yn ion series. Finally, 196 differentially expressed proteins were identified by searching the database ipi.HUMAN.v3.53.

Identification and verification of Amot overexpression in $R L C$-310. Interestingly, MS/MS analysis showed that the protein Amot was differentially expressed in RLC-310 $\left(\mathrm{B} 10^{\mathrm{a}}-47^{\mathrm{b}}\right)$, which has not been reported in ccRCC studies before. The retention time of Amot in gradient elution was 14.24-14.54 min and its experimental isoelectric point was 8.03-7.73. Capillary LC-ESI-MS/MS analysis revealed a preliminary score of 704.6 and 10 matched peptides as shown in Fig. 2A. A significant difference in the mRNA level of Amot was observed between RLC-310 and HK-2 by semiquantitative RT-PCR (Fig. 2B). Significantly high expression of Amot was detected in RLC-310, compared with the Amot protein expression level in HK-2 by western blot analyses (Fig. 2C). Analyses of the Amot protein and mRNA levels further verified the Amot expression difference displayed by the PF-2D system between the two cell lines.

Overexpression of Amot in primary ccRCC tissues. Western blot analysis of 18 tissues using anti-Amot antibody showed an overexpression of Amot in ccRCC tissues, compared with the Amot expression in adjacent normal renal tissues (ANRT) $(\mathrm{n}=18$ : carcinoma tissues, $0.524 \pm 0.262$; normal tissues, $0.183 \pm 0.067$; Student's t-test, $\mathrm{p}<0.01$ ) (Fig. 3). A quantitative analysis of the molecules indicated that the significant difference in the mRNA level of Amot was also observed in all the carcinoma tissues examined $(n=127$ : carcinoma tissues, 

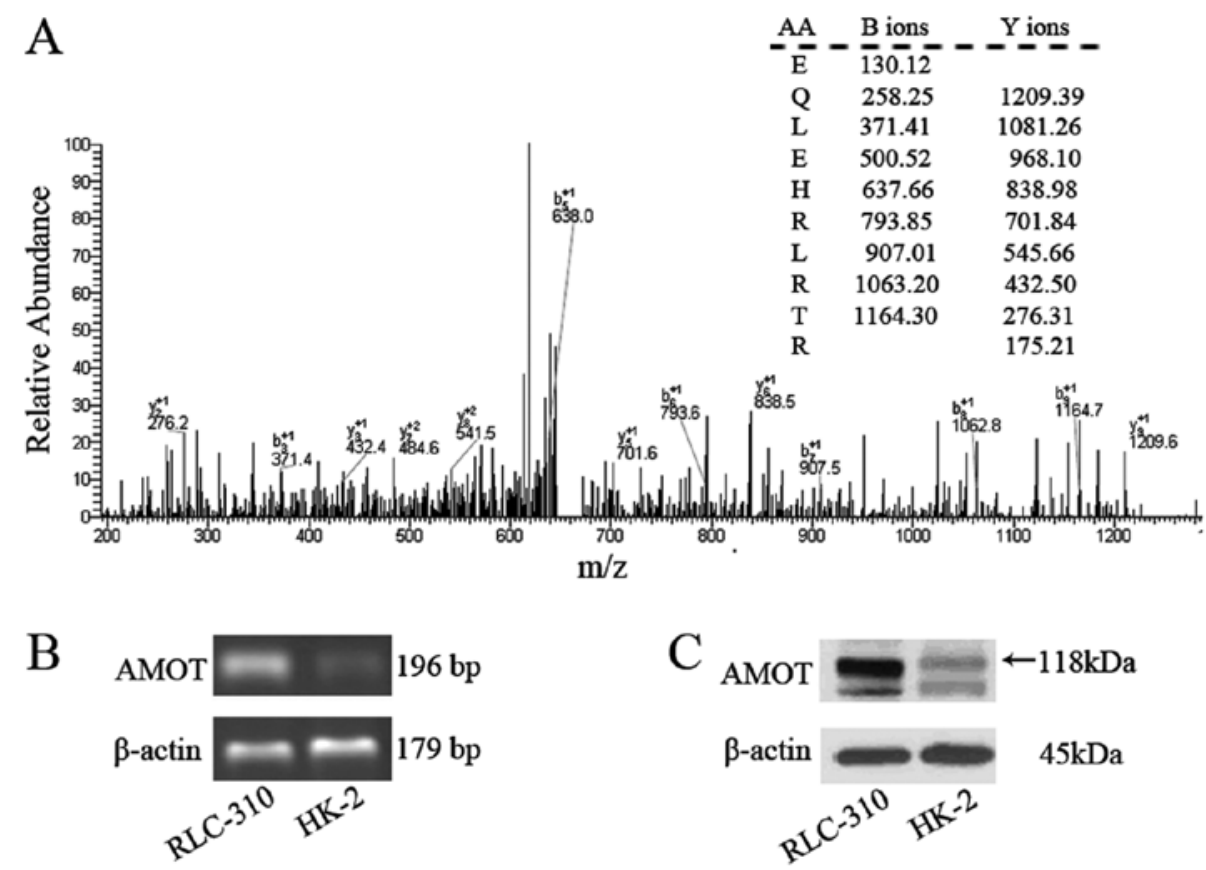

Figure 2. Identification of Amot (angiomotin) and confirmation of its overexpression in RLC-310. (A) Capillary LC-ESI-MS/MS analysis revealed the sequence of matched Amot peptides is EQLEHRLRTR. (B) Amot overexpression in RLC-310 was verified by comparing the Amot expressions in RLC-310 and HK-2 by using semiquantitative RT-PCR analysis. (C) 1-D western blotting.

Table II. Univariate and multivariate analyses of survival rate.

\begin{tabular}{|c|c|c|c|c|}
\hline & $\begin{array}{l}\text { Cases } \\
\text { (n) }\end{array}$ & $\begin{array}{c}\text { 5-year } \\
\text { survival } \\
(\%)\end{array}$ & $\begin{array}{l}\text { Log-rank } \\
\text { test }\end{array}$ & Cox \\
\hline \multicolumn{5}{|c|}{ Stage (Robson) } \\
\hline I & 63 & 77.8 & $<0.0001$ & 0.007 \\
\hline II & 52 & 21.2 & & \\
\hline III/ IV & 12 & 16.7 & & \\
\hline \multicolumn{5}{|l|}{$\begin{array}{l}\text { Histodiffer- } \\
\text { entiation }\end{array}$} \\
\hline Well & 51 & 80.4 & $<0.0001$ & $<0.0001$ \\
\hline Moderately & 61 & 29.5 & & \\
\hline Poorly & 15 & 20.0 & & \\
\hline \multicolumn{5}{|c|}{ Venous invasion } \\
\hline Negative & 67 & 53.7 & 0.039 & 0.677 \\
\hline Positive & 60 & 43.3 & & \\
\hline \multicolumn{5}{|c|}{$\begin{array}{l}\text { Amot RNA } \\
\text { expression }\left(2^{-\Delta \Delta c t}\right)\end{array}$} \\
\hline$\leq 2$ & 28 & 78.6 & 0.001 & 0.036 \\
\hline$>2$ & 99 & 40.4 & & \\
\hline
\end{tabular}

6.03 \pm 4.46 ; normal tissues, 1 ; Student's t-test, $\mathrm{p}<0.01)$. Taken together, our data demonstrated that Amot was overexpressed in ccRCC tissues at both mRNA and protein levels, which is consistent with the observations made in the ccRCC cell lines.
Correlation of Amot expression with clinical and pathological characteristics of $c c R C C$. One hundred and twenty-seven tissue samples from ccRCC patients at different clinical stages were used to investigate the correlation of the Amot expression level with the clinical outcome of ccRCC. Of the 127 patients with ccRCC, 99 had a higher level of Amot expression in ccRCC tissues $\left(2^{-\Delta \Delta c t}>2\right)$ than in ANRT and 28 had a lower level of Amot expression $\left(2^{-\Delta \Delta c t} \leq 2\right)$. The overexpression rate of Amot in ccRCC was $77.95 \%$ (99/127) (Table II). It was shown that Amot overexpression had a significantly high relationship with the poor histodifferentiation of carcinoma cells (crosstabs $\chi^{2}$ test, $\mathrm{p}<0.01$ ) (Fig. 4A), a high relationship with venous invasion (cross-tabs $\chi^{2}$ test, $\mathrm{p}<0.05$ ) (Fig. 4B), but no apparent relationship with the Robson stage (stages I, II and III/IV) for renal carcinoma (cross-tabs $\chi^{2}$ test, $\mathrm{p}>0.05$ ) (Fig. 4C). These results were also confirmed by the Kruskal-Wallis test, a nonparametric test based on completely randomized design for comparisons of more than two samples.

Prognostic significance of Amot expression in ccRCC. The survival analysis using the log-rank test suggested that the overexpression of Amot transcript was probably associated with the poor outcome of ccRCC patients (log-rank test, $\mathrm{p}<0.01$; Fig. 4D). The 5-year survival rates of patients with lowlevel and high-level Amot expressions were 78.6 and $40.4 \%$, respectively. Multivariate analysis was performed using the Cox proportional hazard model to determine whether the prognostic value of the Amot transcript level was independent of other risk factors associated with the clinical outcome of ccRCC. The risk factors examined included Amot transcript expression (low level and high level), venous invasion (negative and positive), histodifferentiation (well, moderately and poorly differentiated) and Robson stage (stages I, II and III/IV). 

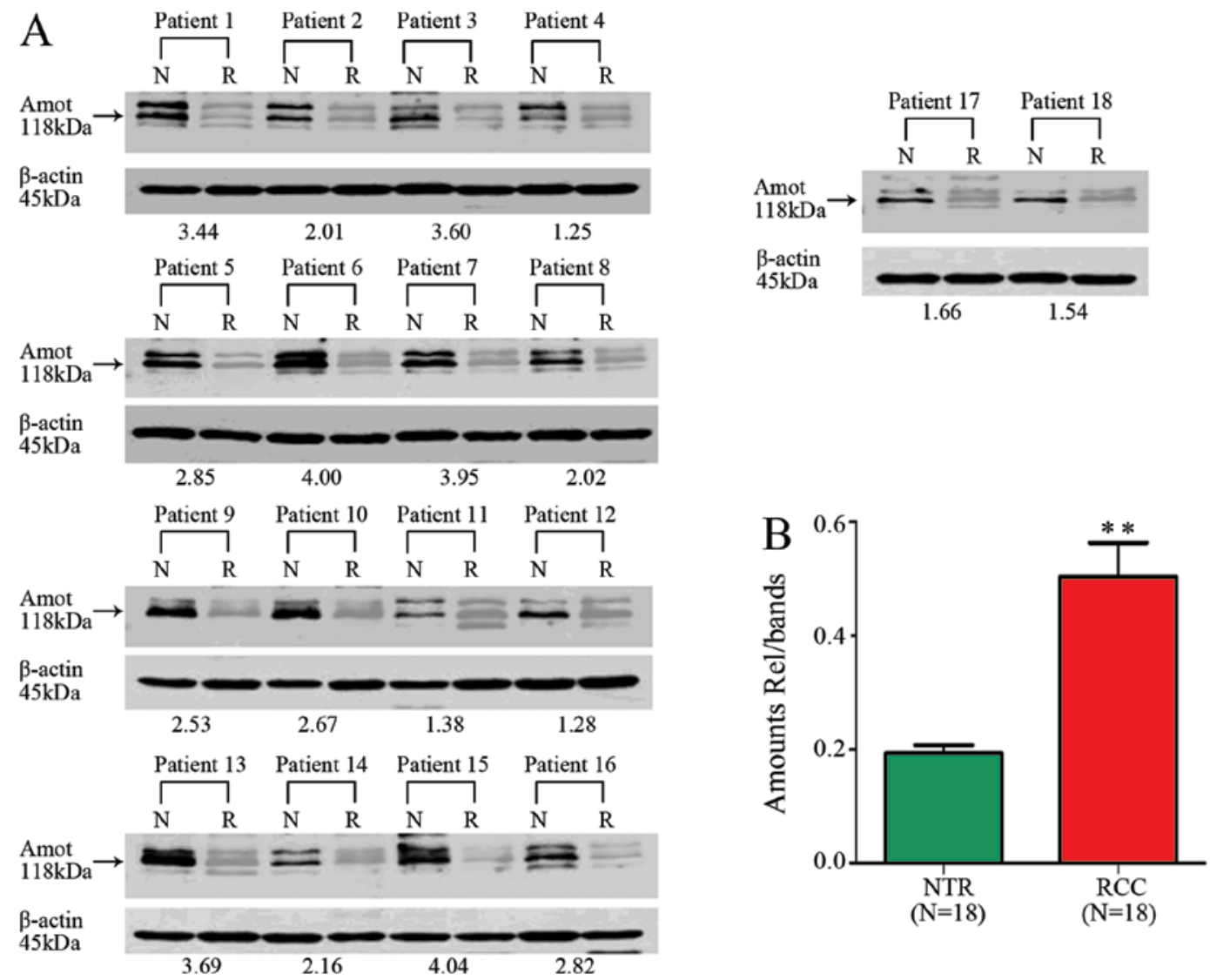

Figure 3. Amot expression in primary clear-cell renal cell carcinoma (ccRCC). (A) Western blot analysis of the 18 paired tissues showed that Amot expressions were higher in primary ccRCC tissues (R), than in corresponding adjacent normal renal cortex tissues $(\mathrm{N})$. The Amot expression in each sample was evaluated on the basis of the ratio of the normalized Amot signal intensity in the primary ccRCC to that in the corresponding normal renal cortex. (B) The Amot was significantly upregulated in all the primary ccRCC. ${ }^{* *} \mathrm{p}=0.0026$ vs adjacent normal renal cortex tissues.
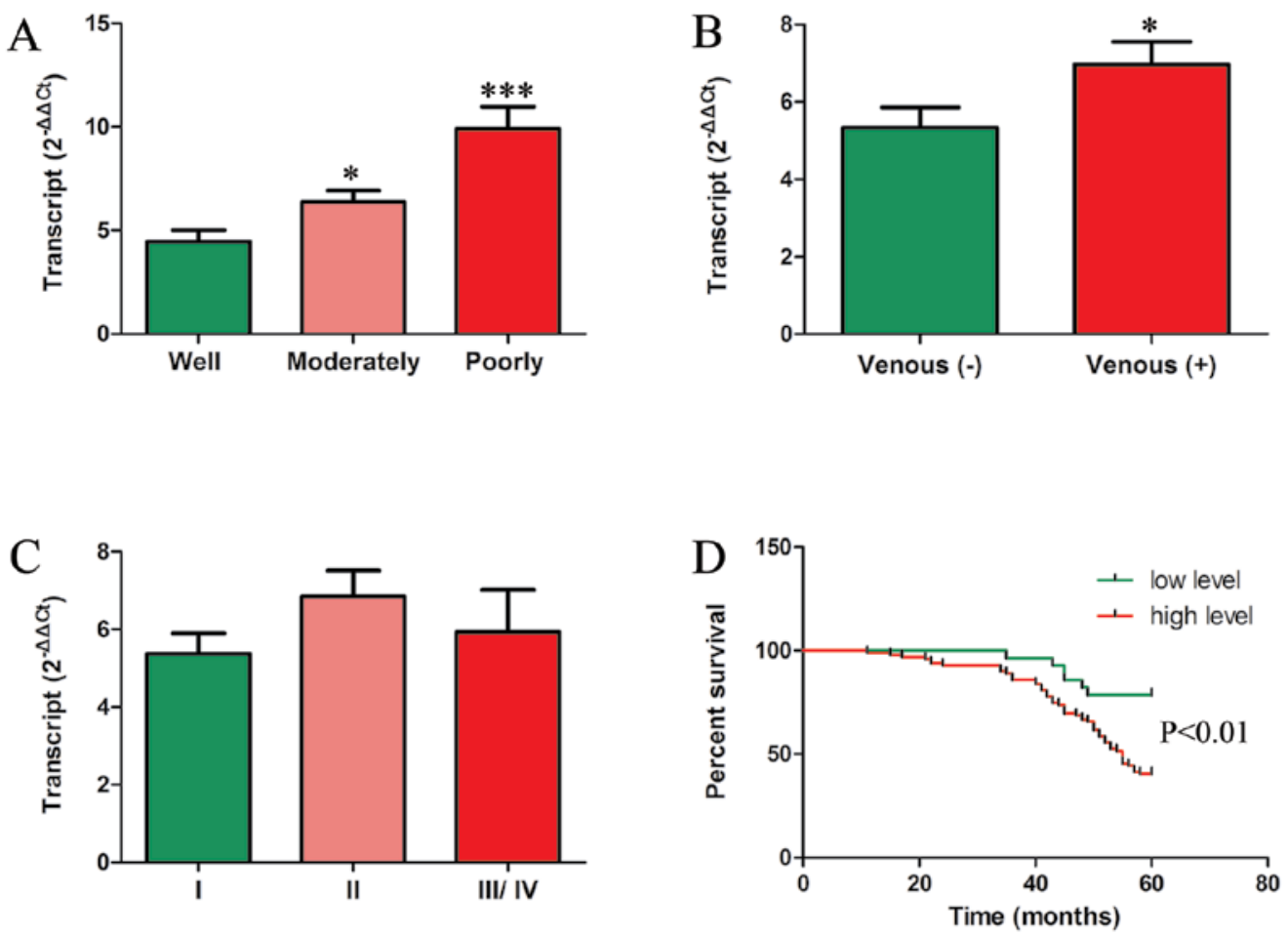

Figure 4. Expressions of Amot transcript in normal and tumor tissues using quantitative real-time PCR. (A) Amot and clinical outcome predicted according to histodifferentiation criteria $\left({ }^{* * *} \mathrm{p}<0.0001,{ }^{*} \mathrm{p}=0.0183\right.$, vs well differentiation). (B) Amot in venous invasion $\left({ }^{*} \mathrm{p}=0.0414\right.$ vs negative venous invasion). (C) Expression levels of Amot and their relationships with Robson grades. (D) Kaplan-Meier survival curves. The survival analysis showed that the high expression of Amot transcript was probably associated with the decreased survival rate of ccRCC patients (log-rank test, $\mathrm{p}<0.05)$. 
Table II shows that as a prognostic factor for the survival of ccRCC patients, the Amot transcript expression was independent of these risk factors $(\mathrm{p}<0.05)$.

\section{Discussion}

In the present study, we compared the global protein profiles of ccRCC RLC-310 and normal renal cell line HK-2 using a PF-2D and capillary LC-ESI-MS/MS-based approach. More than 196 differentially expressed proteins were identified between the carcinoma and normal cell lines. The differential expressions of proteins in ccRCC cell line were functionally related to biological pathways of cell proliferation and antiapoptosis, energy metabolism, mitochondria reduction and oxadation, oxidative stress and resistance, cell signaling, invasion and adhesion, cytoskeleton and motion, neovascularization and others. The extensive protein profile indicated that multiple cellular pathways might be involved in the process of tumorigenesis of ccRCC.

The most striking finding is the initial identification of overexpressed Amot in ccRCC. Its increased expression was also confirmed by RT-PCR and western blot analyses in a cell line. Angiomotin was first identified as KIAA1071 by Kikuno et al in 1999 from a set of size-fractionated human adult and fetal brain cDNA libraries, but its function was unknown (19). Troyanovsky et al have reported that Amot is an angiostatin binding protein and can mediate the angiostatin inhibition of migration and the tube formation of endothelial cells (20). A further study found that the expression of Amot in mouse aortic endothelial cells results in stabilization of tubes in the Matrigel assay and promotes tumor growth and invasion into surrounding muscle tissues in vivo (21). The critical roles of Amot in vascular patterning and endothelial polarization suggest that it may be involved in oncogenesis. Amot has been found to be highly expressed in human breast tumor tissues and linked to angiogenesis (22). However, the expression and role of Amot in RCC have not been experimentally investigated.

After the overexpression of Amot in 18 frozen ccRCC tissues was confirmed by western blot analysis, the expression level of Amot was further investigated by real-time RT-RCR in 127 ccRCC tissues and their corresponding ANRT. The relationships between the Amot expression and the clinical parameters such as Robson stage, histodifferentiation and venous invasion of ccRCC were established. It is notable that the Amot expression in ccRCC was correlated with histodifferentiation and that the overexpression of Amot significantly represented the poor differentiation of ccRCC. On the whole, the ubiquitous overexpression of Amot in ccRCC and its close relationship with ccRCC cell differentiation suggest that Amot may be an important component of ccRCC transformation and development.

The Amot expression showed a significant relationship with venous invasion but no relationship with clinical stages in ccRCC, which are similar to the results of Jiang et al study on human breast cancer (22). Angiogenesis plays an important role in the invasion and dissemination of RCC and is mediated by numerous factors, such as HIF1 $\alpha$ and VEGF. Amot also plays an important role in angiogenesis. Holmgren et al (23) have reported that a combination of DNA vaccines encoding Amot and the extracellular and transmembrane domains of the human EGF receptor 2 (Her-2)/neu oncogene can inhibit breast cancer progression and impaire tumor vascularization in Her-2/neu transgenic mice. A further study found (24) that the anti-Amot B06 antibody can significantly reduce the number of endothelial filopodia and inhibit vessel migration during retinal angiogenesis in vivo and that the systemic or local treatment with this antibody can inhibit the pathological blood vessel formation associated with tumor growth or laserinduced choroid neovascularization of the eye. Recent studies (25) have also shown that electroporation of plasmid coding for the human Amot can significantly delay the progression of autochthonous tumors in cancer prone BALB-neuT and PyMT genetically engineered mice and transplantable TUBO tumor in wild-type BALB/c mice. These studies suggest that the therapy targeting to Amot can restrain pathological angiogenesis around the tumor and may be a new idea for the development of antineoplastics.

Up to the present, the role of Amot in physiological angiogenesis has remained unclear. Wells et al (26) have found that Rich1 binds the scaffolding protein Amot and is thereby targeted to a protein complex at tight junctions (TJs) containing the PDZ-domain proteins and then maintain TJ integrity by the coordinate regulation of $\mathrm{Cdc} 42$ and by linking specific components of the $\mathrm{TJ}$ to intracellular protein trafficking. Aase et al (27) have confirmed that Amot is important for endothelial polarization during migration and can control Racl activity in endothelial and epithelial cells. Recent research (28) has also found that Amot functions downstream of Merlin and upstream of Rich1 and that depletion of angiomotin in Nf2(-/-) Schwann cells attenuates the Ras-MAPK signaling pathway and impedes cellular proliferation in vitro and tumorigenesis in vivo. However, the latest studies $(29,30)$ have found that Amot, as a component of the Hippo pathway, can inhibit Yes-associated protein (YAP) and transcriptional coactivator with PDZ-binding motif (TAZ) oncoprotein by Amot-mediated Hippo-independent tight junction localization. The results of these two studies lead to the question, why did Amot inhibit rather than promote YAP and TAZ oncoprotein? We speculated that it was probably because Amot may play different roles due to its cellular locations and in these two studies, the authors used the normal cell line (human embryonic kidney cell line HEK293), but the biological significance of Amot may differ between renal tumor cells and embryonic kidney cells.

Among proangiogenic factors, vascular endothelial growth factor (VEGF) is the mainstay of tumor angiogenesis $(31,32)$. Clear-cell RCCs (75\%) are strongly associated with mutations of Von Hippel Lindau (VHL) tumor suppressor gene which induces the degradation of hypoxia-inducible factor (HIF-1 $\alpha$ and $\beta$ ) in the presence of oxygen. Therefore, the VHL/HIF-1/ VEGF pathway is deregulated in RCCs and it represents a reasonable therapeutic target for RCCs $(33,34)$. Amot antibodies inhibit FGF-2 and VEGF-induced endothelial migration in the Boyden chamber assay (24). However, Amot-deficient cells have intact response to VEGF in regard to differentiation and proliferation though the chemotactic response to VEGF is abolished in Amot-deficient cells (27). This means that Amotrelated pathways may be VEGF-independent angiogenesis pathways. Further studies need to be conducted to elucidate the role of Amot in tumor pathological angiogenesis. 
In this study, univariate and multivariate analysis revealed that ccRCC patients with strongly positive Amot transcript showed decreased survival, compared with other groups, which indicates that the transcript expression of Amot in ccRCC may be an independent predictor of survival. Although the molecular partners of Amot that promote cancer development were not discovered, Amot displays an unusually high expression in a few cancer types and is correlated with poor outcome of the patients. Jiang et al (22) have confirmed that high levels of Amot transcript are associated with shorter overall survival although they did not use the Cox statistic model to perform multivariate analyses.

This study is the first to identify the overexpression of Amot in ccRCC cells and tissues. Moreover, it is initially reported that its overexpression in ccRCC was associated with poor differentiation, venous invasion and prognosis. Our data suggest that patients who undergo nephrectomy for localized diseases (Robson stage I or II) and whose tumors express high levels of Amot are at increased risk of death. Survival is a major clinical determinant of the outcome of RCC. Thus, once Amot is validated as a reliable prognostic marker for ccRCC, it will contribute to the establishment of individualized followup protocols as well as to the identification of patients suitable for adjuvant therapy in clinical trials. Further studies are needed to determine the prognostic value of this protein in a large spectrum of ccRCC.

\section{Acknowledgments}

This study was supported by National Natural Science Foundation of China (no. 81172171).

\section{References}

1. Jemal A, Bray F, Center MM, Ferlay J, Ward E and Forman D: Global cancer statistics. CA Cancer J Clin 61: 69-90, 2011.

2. Drucker BJ: Renal cell carcinoma: current status and future prospects. Cancer Treat Rev 31: 536-545, 2005.

3. Fisher RI, Rosenberg SA and Fyfe G: Long-term survival update for high-dose recombinant interleukin-2 in patients with renal cell carcinoma. Cancer J Sci Am 6 (Suppl 1): S55-S57, 2000.

4. Messing EM, Manola J, Wilding G, et al: Phase III study of interferon alfa-NL as adjuvant treatment for resectable renal cell carcinoma: an Eastern Cooperative Oncology Group/Intergroup trial. J Clin Oncol 21: 1214-1222, 2003.

5. Gonzalez LJ, Espinosa E and Garcia CI, et al: Sequential therapy in metastatic renal cell carcinoma: pre-clinical and clinical rationale for selecting a second- or subsequent-line therapy with a different mechanism of action. Cancer Metastasis Rev 31 (Suppl 1): S11-S17, 2012.

6. Patard JJ, Pouessel D, Bensalah K and Culine S: Targeted therapy in renal cell carcinoma. World J Urol 26: 135-140, 2008.

7. Rathmell WK and Chen S: VHL inactivation in renal cell carcinoma: implications for diagnosis, prognosis and treatment. Expert Rev Anticancer Ther 8: 63-73, 2008.

8. Audenet F, Yates DR, Cancel-Tassin G, Cussenot O and Roupret M: Genetic pathways involved in carcinogenesis of clear cell renal cell carcinoma: genomics towards personalized medicine. BJU Int 109: 1864-1870, 2012.

9. Cho IC and Chung J: Current status of targeted therapy for advanced renal cell carcinoma. Korean J Urol 53: 217-228, 2012.

10. Simpson RJ and Dorow DS: Cancer proteomics: from signaling networks to tumor markers. Trends Biotechnol 19: S40-S48, 2001.
11. Banks RE, Craven RA, Harnden P, Madaan S, Joyce A and Selby PJ: Key clinical issues in renal cancer: a challenge for proteomics. World J Urol 25: 537-556, 2007.

12. Petricoin EF, Zoon KC, Kohn EC, Barrett JC and Liotta LA: Clinical proteomics: translating benchside promise into bedside reality. Nat Rev Drug Discov 1: 683-695, 2002.

13. Arsanious A, Bjarnason GA and Yousef GM: From bench to bedside: current and future applications of molecular profiling in renal cell carcinoma. Mol Cancer 8: 20, 2009.

14. Nogueira $M$ and Kim HL: Molecular markers for predicting prognosis of renal cell carcinoma. Urol Oncol 26: 113-124, 2008.

15. Wood SL, Rogers M, Cairns DA, et al: Association of serum amyloid A protein and peptide fragments with prognosis in renal cancer. Br J Cancer 103: 101-111, 2010.

16. Yang J, Li A, Yang Y and Li X: Identification of cyclophilin A as a potential prognostic factor for clear-cell renal cell carcinoma by comparative proteomic analysis. Cancer Biol Ther 11: 535-546, 2011.

17. Chen C, Ridzon DA, Broomer AJ, et al: Real-time quantification of microRNAs by stem-loop RT-PCR. Nucleic Acids Res 33: e179, 2005.

18. Chang JT, Chen IH, Liao CT, et al: A reverse transcription comparative real-time PCR method for quantitative detection of angiogenic growth factors in head and neck cancer patients. Clin Biochem 35: 591-596, 2002.

19. Kikuno R, Nagase T, Ishikawa K, et al: Prediction of the coding sequences of unidentified human genes. XIV. The complete sequences of 100 new cDNA clones from brain which code for large proteins in vitro. DNA Res 6: 197-205, 1999.

20. Troyanovsky B, Levchenko T, Mansson G, Matvijenko O and Holmgren L: Angiomotin: an angiostatin binding protein that regulates endothelial cell migration and tube formation. J Cell Biol 152: 1247-1254, 2001.

21. Levchenko T, Bratt A, Arbiser JL and Holmgren L: Angiomotin expression promotes hemangioendothelioma invasion. Oncogene 23: 1469-1473, 2004.

22. Jiang WG, Watkins G, Douglas-Jones A, Holmgren L and Mansel RE: Angiomotin and angiomotin like proteins, their expression and correlation with angiogenesis and clinical outcome in human breast cancer. BMC Cancer 6: 16, 2006.

23. Holmgren L, Ambrosino E, Birot O, et al: A DNA vaccine targeting angiomotin inhibits angiogenesis and suppresses tumor growth. Proc Natl Acad Sci USA 103: 9208-9213, 2006.

24. Levchenko T, Veitonmaki N, Lundkvist A, et al: Therapeutic antibodies targeting angiomotin inhibit angiogenesis in vivo. FASEB J 22: 880-889, 2008.

25. Arigoni M, Barutello G, Lanzardo S, et al: A vaccine targeting angiomotin induces an antibody response which alters tumor vessel permeability and hampers the growth of established tumors. Angiogenesis 15: 305-316, 2012.

26. Wells CD, Fawcett JP, Traweger A, et al: A Rich1/Amot complex regulates the $\mathrm{Cdc} 42$ GTPase and apical-polarity proteins in epithelial cells. Cell 125: 535-548, 2006.

27. Aase K, Ernkvist M, Ebarasi L, et al: Angiomotin regulates endothelial cell migration during embryonic angiogenesis. Genes Dev 21: 2055-2068, 2007.

28. Yi C, Troutman S, Fera D, et al: A tight junction-associated Merlin-angiomotin complex mediates Merlin's regulation of mitogenic signaling and tumor suppressive functions. Cancer Cell 19: 527-540, 2011.

29. Zhao B, Li L, Lu Q, et al: Angiomotin is a novel Hippo pathway component that inhibits YAP oncoprotein. Genes Dev 25: 51-63, 2011.

30. Chan SW, Lim CJ, Chong YF, Pobbati AV, Huang C and Hong W: Hippo pathway-independent restriction of TAZ and YAP by angiomotin. J Biol Chem 286: 7018-7026, 2011.

31. Rini BI: VEGF-targeted therapy in renal cell carcinoma: active drugs and active choices. Curr Oncol Rep 8: 85-89, 2006.

32. Ferrara N and Kerbel RS: Angiogenesis as a therapeutic target. Nature 438: 967-974, 2005.

33. Hu Y, Liu J and Huang H: Recent agents targeting HIF-1alpha for cancer therapy. J Cell Biochem 114: 498-509, 2013.

34. Rathmell WK, Wright TM and Rini BI: Molecularly targeted therapy in renal cell carcinoma. Expert Rev Anticancer Ther 5: 1031-1040, 2005. 